Review Article

\title{
Glutamine Metabolism Is Essential for Stemness of Bone Marrow Mesenchymal Stem Cells and Bone Homeostasis
}

\author{
Tao Zhou (D), Yuqing Yang, Qianming Chen, and Liang Xie $\mathbb{D}$ \\ State Key Laboratory of Oral Diseases, National Clinical Research Center for Oral Diseases, Chinese Academy of Medical Sciences \\ Research Unit of Oral Carcinogenesis and Management, West China Hospital of Stomatology, Sichuan University, 610041 Chengdu, \\ Sichuan, China
}

Correspondence should be addressed to Liang Xie; lxie@scu.edu.cn

Received 2 May 2019; Accepted 23 August 2019; Published 12 September 2019

Guest Editor: Jun Li

Copyright (c) 2019 Tao Zhou et al. This is an open access article distributed under the Creative Commons Attribution License, which permits unrestricted use, distribution, and reproduction in any medium, provided the original work is properly cited.

Skeleton has emerged as an endocrine organ which is both capable of regulating energy metabolism and being a target for it. Glutamine is the most bountiful and flexible amino acid in the body which provides adenosine $5^{\prime}$-triphosphate (ATP) demands for cells. Emerging evidences support that glutamine which acts as the second metabolic regulator after glucose exerts crucial roles in bone homeostasis at cellular level, including the lineage allocation and proliferation of bone mesenchymal stem cells (BMSCs), the matrix mineralization of osteoblasts, and the biosynthesis in chondrocytes. The integrated mechanism consisting of WNT, mammalian target of rapamycin (mTOR), and reactive oxygen species (ROS) signaling pathway in a glutaminedependent pattern is responsible to regulate the complex intrinsic biological process, despite more extensive molecules are deserved to be elucidated in glutamine metabolism further. Indeed, dysfunctional glutamine metabolism enhances the development of degenerative bone diseases, such as osteoporosis and osteoarthritis, and glutamine or glutamine progenitor supplementation can partially restore bone defects which may promote treatment of bone diseases, although the mechanisms are not quite clear. In this review, we will summarize and update the latest research findings and clinical trials on the crucial regulatory roles of glutamine metabolism in BMSCs and BMSC-derived bone cells, also followed with the osteoclasts which are important in bone resorption.

\section{Introduction}

Bone is a relatively dynamic organ which provides stiffness, shape, support, and locomotion for body structures [1]. It undergoes modeling and constant remodeling throughout life, exhibiting structure and shape changes. Bone modeling occurs from birth to adulthood and is responsible for gaining mass and changing the skeletal structure, as exemplified by the increases in bone length and diameter. Bone remodeling, tightly coupling bone resorption and formation, behaves the substitute for old tissues by new bones, thereby maintaining the mineral homeostasis and strength [2]. Osteoblasts for bone formation and osteoclasts for bone resorption are the main cells involved in bone remodeling; meanwhile, osteocytes derived from osteoprogenitors are also crucial in this biological process [3-6]. Recently, emerging evidences support that bone is an endocrine organ and manifests active metabolism, where cell bioenergetics plays an essential role in regulating intermediary metabolism $[1,7]$. Collaboratively signaling networks contribute to an efficient transition in organisms between anabolic and catabolic states; thus, bone cells are capable to survive and grow in environments in which nutrient availability differs.

Virtually, biosynthesis requires amounts of exogenous fuel uptake, which can be converted to hydrolysis of adenosine $5^{\prime}$-triphosphate (ATP) inside the body to drive all cellular processes later [8]. The fuel sources containing glucose, free fatty acids, and the amino acids are excellent substrates for generating ATP in both cytoplasm and mitochondria through oxidative phosphorylation [9-11]. Their consumption and catabolism are adjusted automatically in order to match the distinctive energy demands in different stages covering proliferation, differentiation, and apoptosis, in which intracellular signaling molecules serve as checkpoints 
for fuel selection, storage, transport, and utilization [12]. In addition, extrinsic factors like glucocorticoids also change the fuel metabolism and biological behavior of bone cells in result [13].

Previous studies supported that glutamine metabolism as a regulatory node participated in many biological processes, including vessel formation, cancer progress, and immune regulation [14-16]. Recently, glutamine in bone homeostasis gained increasing concentration in mediating the proliferation, osteoblast, and adipocyte differentiation, immunological features of cell BMSCs [17]. Alternatively, the bioenergetics of osteoblasts, osteocytes, and even the adipocytes were also regulated directly or indirectly by glutamine metabolism, which were tightly related to the degenerative diseases such as osteoporosis. Mechanistically, it was elucidated that $\mathrm{WNT} / \beta$-catenin signaling, mammalian target of rapamycin signaling (mTOR), hypoxia-inducible transcription factors (HIFs), and some other signaling pathways were involved in bone cell metabolic activities [18-20]. In this paper, we reviewed and updated the crucial regulatory roles of glutamine metabolism in BMSCs, BMSC-derived bone cells, and osteoclasts which expected to provide a novel therapeutic perspective for bone destructive disorders.

\section{Glutamine Metabolism}

Glutamine, a nonessential amino acid (NEAA) composed of carbon (41.09\%), hydrogen (6.90\%), oxygen $(32.84 \%)$, and nitrogen $(19.17 \%)$, is mainly synthesized by the enzyme glutamine synthetase (GS) using glutamate and ammonia $\left(\mathrm{NH}_{3}\right)$ as a source. As the most bountiful and flexible amino acid in the body, it represents about $20 \%$ of the total free amino acids pool in the blood and $40 \%$ to $60 \%$ of the total amino acid pool in certain tissues [21-23]. Glutamine is hydrolyzed by glutaminase (GLS) to ammonium-ion $\left(\mathrm{NH}_{4}\right)$ and glutamate, the latter is subsequently transformed to $\alpha$-ketoglutarate $(\alpha-\mathrm{KG})$ occurring as a transamination or a deamination [24]. Then, $\alpha$-KG enters the tricarboxylic acid cycle (TCA cycle) to generate ATP through the production of nicotinamide adenine dinucleotide (NADH) and flavin adenine dinucleotide $\left(\mathrm{FADH}_{2}\right)$ [25]. Rather than being a substitute fuel source in TCA cycle, glutamine is also used as substrate for constructing proteins and nucleotides [26]. The nitrogen from glutamine through the practice of aminotransferases maintains the degrees of numerous amino acid pools in the cell, as exemplified by more than $50 \%$ of NEAAs originated from glutamine are used in protein synthesis in cancer cells in vitro [27]. It is indicated that, in cancer cells, mutations in TCA cycle enzymes, fumarate hydratase $(\mathrm{FH})$ and succinate dehydrogenase $(\mathrm{SDH})$, or complexes of the electron transfer chain (ETC), such as complex I and complex III, could promote glutamine utilization. In other words, TCA cycle, $\mathrm{FH}, \mathrm{SDH}$, and ETC are involved in its participation of nonessential amino acid production. For example, taken in by the cell through a transporter, glutamine is deaminated to glutamate by cytoplasmic GLS1, transferred by SLC25A11 into the mitochondrial matrix, and converted into $\alpha$-KG. Then, $\alpha$-KG follows TCA cycle steps until oxaloacetic acid, which is then converted into aspartate by aspartate transaminase (GOT2) and exported into the cytoplasm, which is critical to both purine and pyrimidine biosynthesis. After that, Asparate may be transformed into asparagine and arginine. In addition, glutamate in cytoplasm could be converted into arginine and proline [28-30]. Besides, glutamine also powers fatty acid synthesis through reductive carboxylation [31].

Glutamine metabolism was first put forward in 1935 by Hans Krebs, who reported that the brain cortex and retina of vertebrates and the kidney of rabbits and Guinea pigs could synthesize glutamate into glutamine and hydrolyze glutamine to ammonium glutamate [32]. Developing over time, much is known about the importance of glutamine metabolism in pathological conditions. Some tumor cells utilized glutamine to provide both nicotinamide adenine dinucleotide phosphate (NADPH) and carbon for lipid and glutathione biosynthesis as well as nitrogen for nucleotide biosynthesis, which was essential in controlling oxidative stress and supporting proliferation [33, 34]. Moreover, glutamine metabolism is also critical for liver-to-pancreas transdifferentiation, mature adipocyte inflammatory responses, and immunological cell functions [35-37]. And glutamine metabolism impacted epigenetic states as well as genome organization via $\alpha-\mathrm{KG}$, eventually altered cellular differentiation decisions [38]. More than 30 years ago, Biltz et al. firstly reported an active consumption and metabolism of glutamine in isolated calvaria and long bones [39]; subsequently, the role of glutamine in bone has drawn increasing attention.

\section{Glutamine Metabolism in BMSCs}

BMSCs, known as nonhemopoietic multipotent mesenchymal cells, are traditionally capable to differentiate into osteoblasts, adipocytes, and chondrocytes, thereby regulating bone homeostasis [40-42]. Recently, the energy metabolisms including glucose metabolism, glutamine metabolism, and fatty acids in MSCs in various contexts are reported constantly [43-45]. Glucose is a major energy and carbon source for mammalian cells and has been known as a major nutrient for osteoblasts since the early 1960s [46]. Instead of energy supplement, aerobic glycolysis in osteoblasts may be linked with the citrate secretion, which plays a critical role in the formation of apatite nanocrystals in bone $[47,48]$. Therapeutic strategies that target glucose metabolism tend to apply to patients diagnosed with systemic diseases such as type 2 diabetes mellitus and chronic kidney disease $[49,50]$. Moreover, Thrailkill et al. suggested that treatment with insulin alone only partially corrected both hyperglycemia and diabetic bone phenotype in twelve-week-old diabetic mice, which means the therapy targets in other metabolism are required [51]. Fatty acids, generated from stored triacylglycerides or fat depots and released into the circulation, are degraded in the mitochondria for the generation of ATP in bone cells, while the amount that is utilized for ATP production is currently unknown [52]. Similar to fatty acids, the extent that amino acids contributes to oxidative phosphorylation remains unclear at present; however, there are increasing numbers of researches on glutamine. Glutamine as the 


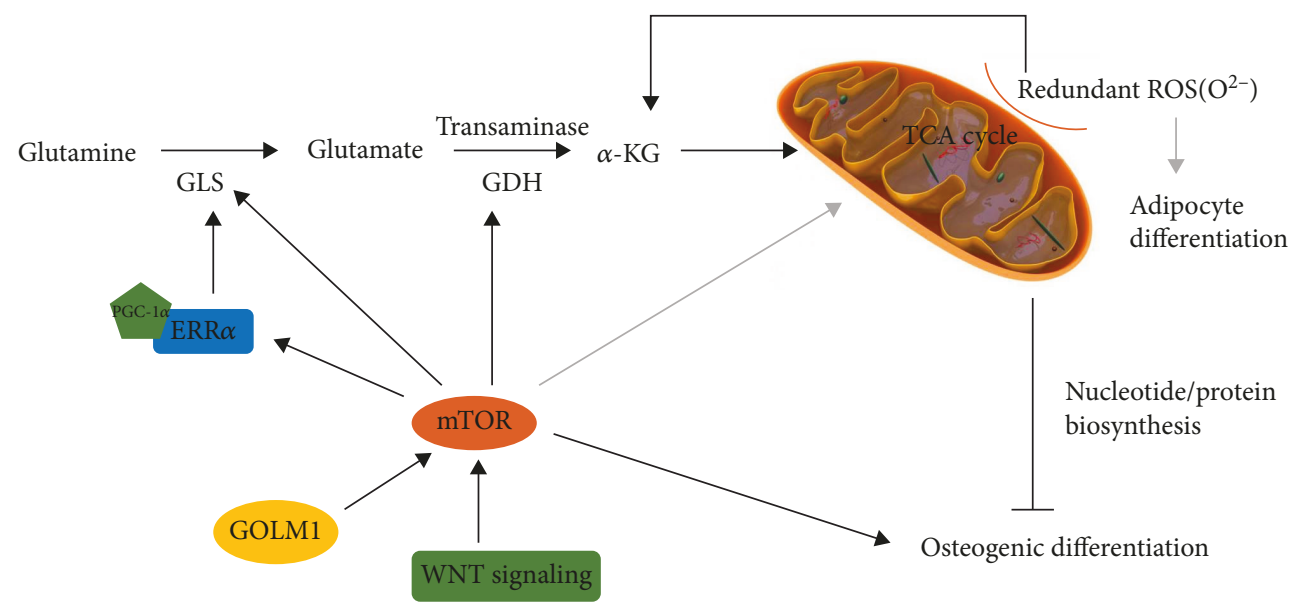

FIgURE 1: Glutamine-dependent regulation of BMSC osteogenic and adipocyte differentiation. The black arrows represent the signaling pathway in osteogenic differentiation regulated by glutamine; meanwhile, the gray arrows represent the signaling pathway in adipogenic differentiation.

second critical regulator after glucose exerts an essential modulation in BMSC proliferation, lineage allocation, osteoblast specification, and even the immunomodulatory properties.

3.1. Glutamine Metabolism in BMSC Proliferation. With regard to the proliferation of cells, Eagle et al. initially described the importance of glutamine in cell proliferation in vitro and meticulously essential for MSC proliferation [53]. In synchronized HeLa cells, glutamine, as well as glucose, is required for progression through the restriction point in mid-to-late G1. And glutamine is the only essential substrate for the progression through $\mathrm{S}$ phase into cell division, which was also indicated by combining pulse-chase LC-MS-based isotope tracing with computational deconvolution and metabolic flux modeling in synchronized cell populations [54, 55]. Mechanistically, glutamine has been reported to progress through the restriction point in midto-late G1 as well as exit S phase that was efficient for cell division beginning [54]. It is indicated that glutamine could enhance the expression of cyclin D1 and D3 and regulate cyclin-dependent kinase (CDKs) that were able to promote the passage into $S$ phase and downregulate $\mathrm{p} 21$ expression, a key regulator for the cycle checkpoint of G1/S [56]. And this phenomenon may be associated with GLS, since glutamine increased the activity of GLS and glutamate dehydrogenase (GDH) through the mTOR/S6 and MAPK pathways in a dose-dependent manner, which finally promoted the cell proliferation [57]. However, the concrete mechanism remains unclear currently. In addition, it is commonly accepted that glutamine provided precursors for downstream synthetic steps, such as the DNA replication in $S$ phase and lipid synthesis in G2 phase. And the majority of TCA carbons and nitrogen of some NEAAs derived from degraded glutamine in endothelial cells $[15,58]$. Glucose is a major energy and carbon source for mammalian cells and has been known as a major nutrient for osteoblasts since the early 1960s. What is more, glutamine also provides a small amount of energy, since the glutamine-consuming enzymes are found largely in mitochondria and far from the primary need for ATP. Additionally, Karner's group found that BMSC proliferation and colony expansion were largely correlated with amino acid transaminase-dependent $\alpha$-KG production, which could partially explain the negative impact of reduced GLS activity on BMSC proliferation [17]. However, the contribution of other amino acid biosynthesis derived from glutamine metabolism to BMSC proliferation has not been clear yet [33,59]. For tumor cells in other tissues, glutamine satisfies biosynthetic and bioenergetic demands of these cells via anaplerotic entry to the TCA cycle and reductive carboxylation, thus regulating cell survival and proliferation $[60,61]$. In contrast, the proliferation rates of skeletal progenitor cells seemed less important connection with glutamine-dependent reductive carboxylation or TCA cycle anaplerosis, which suggested distinctive roles of glutamine metabolism in different types of cells [19].

3.2. Glutamine Metabolism in BMSC Differentiation. Osteogenic and adipocyte differentiations are the pivotal linage commitments of BMSCs in skeletal development. BMSCs consume and metabolize a significant amount of glutamine as they undergo differentiation into the osteoblast but not the adipocyte lineage. As BMSCs differentiated toward osteoblasts, glutamine metabolism provided ATP through the TCA cycle with a declined contribution to citrate [17]. Furthermore, an integrated mechanism in a glutaminedependent pattern was involved to meet energetic and synthetic demands during BMSC differentiation (see Figure 1).

3.2.1. GLS. Mitochondria is a pivotal place covering many complex metabolic reactions [62]. GLS catabolizes glutamine into glutamate, then $\alpha-\mathrm{KG}$, which replenishes anaplerosis of TCA intermediates to maintain mitochondrial activity and supply metabolic intermediates for active biosynthesis in osteogenesis [63]. Experimental evidence suggested GLS as the targeted enzyme of glutamine metabolism which influenced the differentiation of BMSCs. Genetically inhibiting glutamine metabolism via deletion of Gls in BMSCs resulted in reduction of overall osteoblast numbers and capability of 
bone information, consequently causing decreased bone mass relative to wild-type littermates [17]. Alternatively, miRNA as an important regulator was able to establish a complex circuit in bone homeostasis by interacting with different genes [64]. Recent evidences reported that miRNA-206 participated BMSC bioenergy by directly bounding to the $3^{\prime}$-untranslated region $\left(3^{\prime}\right.$-UTR) of GLS mRNA, which resulted in the suppression of GLS expression and glutamine metabolism and eventually inhibited the osteogenic differentiation of BMSCs [65].

3.2.2. mTOR. mTOR is a sensor of growth factors whose activation increases bone width and mass as a result of hyperproliferated MSCs but declines bone length and mineral contents due to defective MSC differentiation [66]. Mechanistically, mTOR is a central target of intrinsic control in bone cells which integrates various molecules associated with glutamine metabolism in BMSC differentiation. Previous studies indicated WNT signaling influenced osteoblasts biological behaviors by enhancing both cell numbers and protein synthesis activity [67]. Importantly, to meet the increased energetic and synthetic need, the anabolic mechanism directly responded to WNT signaling to impact osteoblast differentiation of BMSCs. WNT signaling targeted the mammalian target of rapamycin complex1 (mTORC1) to stimulate glutamine entry to the TCA cycle, subsequently it lowered intracellular glutamine levels. Then, the general control nonderepressible 2-mediated (GCN2-mediated) with integrated stress response (ISR) pathway was triggered due to the WNT-induced reduction of glutamine, which stimulated the expression of genes that responsible for amino acid transport, tRNA aminoacylation, and protein folding [68]. Previous studies also suggested that mTORC1 activation stimulated glutamate to $\alpha$-KG conversion by activating GDH, thus promoting cancer cell proliferation [69]. The activation of mTOR signaling pathway stimulated by Golgi membrane protein 1 (GOLM1) overexpression in BMSCs was in sympathy with that in cancer cells, behaving inhibited osteogenic differentiation of BMSCs due to increased GDH activity and glutamine to $\alpha$-KG conversion. [20].

3.2.3. ERR $\alpha$. Estrogen-related receptor $\alpha(\mathrm{ERR} \alpha)$, an orphan nuclear hormone receptor, is capable of regulating the transcription of related genes. Previous studies reported that $\mathrm{ERR} \alpha$ positively regulated adipocytic and chondrocytic differentiation of MSCs while behaved a dual effect on osteoblast differentiation in Runx2- and/or WNT-target manner [70]. Recently, the age-related restriction of BMSCs has been reported as an essential factor in bone degenerative progress because of declined osteogenic capacity and unbalanced lineage allocation [71, 72]. And the dynamic expression patterns of ERR $\alpha$ with ages were tightly associated with BMSC osteoblast differentiation. A study displayed that ERR $\alpha$ expression was obviously reduced in elder rats, which was consistent with the deteriorated osteogenic capacity with ages [73]. Besides, ERR $\alpha$ was dysregulated in ageprevalent diseases like osteoarthritis and rheumatoid arthritis [74, 75]. As for cell level, ERR $\alpha$ reached peak protein expression levels at early phase of osteoblast differentiation and declined at mineralization stage while mRNA levels remained stable. It indeed supported the view that ERR $\alpha$ was inactivated after the onset of osteoblast maturation and it regulated osteoblast differentiation in a time-specific manner [76]. However, precise molecular mechanism remains unclear. Dysregulation of mitochondrial function is a common feature of aging, and coactivation of ERR $\alpha$ with proliferator-activated receptor gamma coactivator 1$\alpha$ (PGC- $1 \alpha)$ regulated mitochondrial biogenesis through fatty acid oxidation and energy expenditure related to ROS [77, 78]. Through binding to its promoter, ERR $\alpha$ directly regulated GLS expression, leading mitochondrial Gln-dependent anaplerosis critical to TCA cycle and biosynthesis of nucleotides and proteins. Aging negatively impacted on this ERR $\alpha /$ GLS signaling pathway, and repaired ERR $\alpha$ and GLS expression could partially restore osteogenic capacity of MSCs to resist bone loss [73]. In addition, the synthesis master regulator mTOR modulated ERR $\alpha /$ GLS signaling via affecting ERR $\alpha$ transcriptional activity, which may be a targeted therapy for agingrelated bone loss [73].

3.2.4. ROS. Reactive oxygen species (ROS) originate from the oxidation of metabolic intermediates of ETC and are usually produced in the form of superoxide in the mitochondria [79]. The complexes of the respiratory chain in mitochondria are the main ROS production sites, especially complexes I and III. Besides, many other proteins such as pyruvate dehydrogenase (PDH) and electron transfer flavoprotein (ETF) are also ROS producers [80]. ROS are not only a consequence of differentiation but also are critical components of pathways regulating stem cell differentiation [81]. They are precisely regulated to prevent oxidative damage of cells in normal circumstances; elevated ROS in BMSCs with ages were reported to destruct the lineage allocation, displaying promoted adipogenesis and blocked osteogenesis [82, 83]. A potential mechanism may be the toxic accumulation of $\alpha$-KG under excessive oxidative metabolism. Increased activity of PDH and loss of mitochondrial membrane potential (MMP) with a transformation to TCA cycle most likely enhanced pyruvate entry into mitochondria, thus accumulating toxic metabolites [84]. Then, it resulted in nucleocytoplasmic vacuolation and chromatin condensation which obviously prevented osteogenic and adipocyte differentiation. Simultaneously, the accompanying DNA damage, inhibition of histone $\mathrm{H} 3$ (Lys27) of acetylation, and increased HIF- $1 \alpha$ degradation contributed to the death of BMSCs [84]. Moreover, another study reported that increased glutathione content from glutamine was important to offset the detrimental effect of ROS to the osteoblast fate [17]. Alternatively, compared with the positive role of ROS, glutamine was less chief in adipocyte differentiation of BMSCs. The mitochondrial-generated ROS enhanced adipocyte differentiation in a mTORC1-dependent pattern, which could explain the phenomenon that neither glutamine consumption nor GLS activity altered during adipocyte differentiation relative to undifferentiated BMSCs $[85,86]$. 
3.3. Glutamine Metabolism of BMSCs in Osteoimmunology. Apart from the self-renewal and multilineage differentiation features, MSCs are known to exert an immunosuppressed modulation by expressing adhesion molecules and secreting effectual factors like cytokines, chemokines, and growth factors [87-89]. Researches about glutamine metabolism in immune system in recent decades also prompted the recognition of its regulatory role in adaptive immunity and innate immunity, covering lymphocytes, neutrophils, and macrophages as well as a series of cytokines [90-92]. In BMSCs, the concentration of glutamine was relevant to their immunology properties. High dose of glutamine displayed an enhancement for immunosuppressive properties of BMSCs via affecting inflammatory cytokines, displaying decreased levels of proinflammatory cytokines like interleukin- $1 \beta$ (IL$1 \beta$ ) and IL- 6 and increased levels of anti-inflammatory cytokines IL-10, and transforming growth factor- $\beta$ (TGF- $\beta$ ) [93]. Mechanistically, varied production of proinflammatory cytokines may relate to the reduced expression of phosphorylated nuclear factor kappa-B (NF- $\kappa$ B) and high level of signal transducer and activator (STAT-3) in BMSCs as they control cytokine production [94]. Additionally, IL-10 was critical in immune responses in glutamine concentration as they inhibited activation of NF- $\kappa \mathrm{B}$, thus modulating the cytokine production. Meanwhile, both IL-10 and STAT-3 increased in BMSCs with glutamine, which could be explained that the anti-inflammatory effects of IL-10 were mediated by STAT-3, and in turn, IL-10 was also reported to promote STAT-3 to reduce amounts of proinflammatory cytokines $[95,96]$. Additionally, the proliferation of lymphocytes and macrophages was inhibited when cocultured with BMSCs in glutamine medium, both followed with an increased production of IL-10 [97]. The increased IL-10 may be attributed to the transformation of macrophages to an anti-inflammatory M2 phenotype with the induction of MSCs [98], whereas the precise mechanism of immunomodulation in BMSC-mediated glutamine is unclear.

\section{Glutamine Metabolism in Osteoblasts}

Characterized as the chief bone-making cells, osteoblasts take charge of producing large amounts of both collagen I-rich bone matrix and ectoenzymes controlling matrix mineralization. They follow timely programmed steps and express specific genes under the control of proosteogenic pathways. WNT signaling pathway is pivotal to promote the commitment towards an osteo/chondroprogenitor of BMSCs, especially in the early steps in osteoblast differentiation [99]. It is suggested that WNT signaling directly reprograms cellular metabolism in osteoblast lineage cells by stimulating aerobic glycolysis, glutamine catabolism, and fatty acid oxidation [67]. Additionally, glutamine catabolism has been identified as a crucial regulatory step in satisfying both energetic and synthetic requirements which is connected with WNT-induced bone anabolism in immature osteoblasts.

Karner et al. reported that glutamine was both an energy source and a protein-translation rheostat which was responsive to osteoblast differentiation [68], and impaired osteo- blast differentiation with ages in BMSCs may be linked with declined glutamine consumption [73]. Meanwhile, Brown et al. supported that glutamine significantly improved osteoblast viability and enhanced the utilization of glucose in both human osteoblast-like cell lines and mouse calvarial osteoblasts, and higher levels of osteocalcin expression were beneficial for matrix mineralization [100]. Furthermore, considering that glutamine directly stimulated collagen typelal transcription in fibroblasts, the practice of glutamine on mineralization in osteoblast cultures might be owing to an influence on collagen expression [101]. However, it remains unknown whether glutamine anaplerosis is required for physiological osteoblasts activity in bone formation due to the lack of systematic analyses in osteoblasts with Gls depletion [102].

\section{Glutamine Metabolism in Chondrocytes}

The commitment of BMSCs to the chondrogenic lineage is a significant event to initiate the endochondral ossification that BMSCs firstly give rise to immature chondrocytes and cartilage primordia. Integrated signaling among growth factors and components of the extracellular matrix containing collagens, proteoglycans, glycosaminoglycans (GAGs), and proteases regulate chondrocytes collaboratively to facilitate progressive changes in endochondral ossification and bone formation [103]. Glutamine was initially shown to sustain glycosaminoglycan and protein synthesis as a carbon and nitrogen provider in extracellular matrix metabolism in chondrocytes [104]. In view of the special avascular environment of cartilage, it was widely assumed that cells within cartilage were hypoxic and hypoxia regulated the energetic state of maturing cells [105]. However, an excessive hypoxic environment was harmful for chondrocytes, and it was usually followed with a reduced utilization of glutamine and declined content of glutathione, which was possibly attributed to the downregulated mitochondria 1 function and inhibited oxidative deamination [105]. HIF- $1 \alpha$ is a protein expressing in hypoxic microenvironment, and higher expression of HIF$1 \alpha$ under hypoxic condition is of great necessity for chondrocytes survival in an intrinsic mechanism [106, 107]. As HIF$1 \alpha$ mediated an upregulated expression of GLS1, the flux of glutamine to $\alpha$-KG was enhanced to favor $\alpha$-KG-dependent proline and lysine hydroxylation of collagen, and it was beneficial to increase bone mass by endowing the resistance of the cartilaginous matrix to protease-mediated degradation [108]. In some pathological situations, glutamine also exhibited a protective effect on chondrocytes. For instance, glutamine upregulated glutathione concentration in chondrocytes to protect cells from injury in surgery or infectious conditions $[109,110]$. In stress conditions, glutamine exerted chondroprotective effect by enhancing the expression of heat shock protein 70 (HSP70), which reduced chondrocytes apoptosis to prevent the progress of cartilage degeneration [111]. Importantly, two energy-dependent anabolic processes collaboratively regulated the biological behavior in chondrocytes. The imbalance of glucose-mediated reduced collagen synthesis and glutamine-mediated increased bone mass in chondrocytes will lead to the skeletal dysplasia [108]. 


\section{Glutamine Metabolism in Osteoclasts}

To maintain skeletal architecture and strength, a homeostatic balance between new bone formation and old or damaged bone resorption is required. Osteoclasts derived from the hematopoietic lineage mainly degrade bone matrix and liberate the calcium and phosphate, eventually exhibiting regulation on bone mass as well as quality [112]. It was suggested that L-glutamine had a significant impact on early phase of osteoclast differentiation and maturation stage [113]. Following the uptake through SLC1A5, a Na ${ }^{+}$-dependent transporter of L-glutamine [114-116], osteoclasts converted glutamine to glutamate and then to $\alpha-\mathrm{KG}$, which was important as an anaplerotic substrate in osteoclast differentiation [117]. Additionally, glutamine was an essential fuel for the acquisition of bone-resorbing activity in mature, multinucleated osteoclasts [113]. Morten et al. reported that hypoxia stimulated glutamine consumption in osteoclasts, which was similar to SK-N-SH neuroblastoma and A549 lung adenocarcinoma cells $[118,119]$. The increased glutamine uptake may mainly contribute to biosynthesis as glutamine withdrawal had no effect on either ATP production [61].

\section{Therapeutic Potential of Glutamine in Bone Disorder Treatment}

Energetic metabolism has gained improving attentions in the past decades for the regulation in the delivery and utilization of nutrients throughout the body, and the metabolic inflexibility is associated with various pathological process [120]. In updated clinical trials, amounts of researches have been arisen to elucidate the influence of glutamine in the improvement of adverse reactions induced by treatments and the potential applications in diagnosis (see Table 1). Additionally, glutamine is pivotal for both energy production and redox homeostasis in bone homeostasis, which can be a potential strategy in bone diseases such as osteoporosis and osteoarthritis.

7.1. Osteoporosis. Osteoporosis, mainly occurring in postmenopausal women and elder group, is characterized by low bone mass and deterioration of the bone microarchitecture which eventually behaves increased fracture susceptibility [151]. Previous researches reported aging-related changes of glutamine metabolism in osteoporosis could break the balance between osteogenic and adipocyte differentiation of BMSCs through key enzyme destruction in glutamine metabolism or mitochondria metabolic deterioration $[73,84]$. Early anabolic therapies associated with glutamine may be a good way to treat osteoporosis from the perspective of etiology. Glutamine supplement (L-glutamine/L-alanyl solution $(2.0 \mathrm{ml} / \mathrm{kg})$ through the tail veins in the first $7 \mathrm{~d}$ was noted to obtain quicker and more regular primary callus and cartilaginous callus through attainments of positive nitrogen balance in standardized albino rats, which was instrumental in the healing of fractured osteoporosis patients [152]. However, the effect was tiny on enhancing the quality of fracture healing under conditions of stress, only exhibiting some influence on the speed of healing [152]. Vir- tually, glutamine precursor has been explored to apply in the treatment of osteoporosis in animal model. 2-Oxoglutarate (2-Ox), a precursor of glutamine, has been identified to promote the thickness of cancellous bone, growth plate, and articular cartilage in fundectomy-induced osteopenic bone [153]. It was also applied in osteoporosis induced by glucocorticoid treatment in premature infants with inflammatory and autoimmune disorders, which improved levels of growth hormone and osteocalcin concentration and preserved microarchitecture of trabecular bone [154].

7.2. Osteoarthritis. Osteoarthritis, characterized by degeneration of the articular cartilage and subchondral bone pathologically, is often diagnosed by the symptoms of pain, joint stiffness, and disability [155]. In osteoarthritis patients, inflammatory cytokines and ROS are induced by nonphysiological mechanical loading and heat stress facilitated by deviant joint movements, eventually contribute to the pathological progression. The treatment of chondrocytes with glutamine protected cells from heat stress and NO-induced apoptosis, thereby preventing osteoarthritis [111]. Fujita et al. indicated that heat stimulation and glutamine could stimulate the expression of HSP70 in rat articular cartilage in vivo, which may be involved in the suppression of osteoarthritis progression [156]. As stem cell-based therapy is a potential approach for osteoarthritis, researches about cellular metabolism in stem cells contribute to the application of cell-based treatment in general. Stegen et al. suggested that HIF- $1 \alpha$-mediated conversion of glutamine to glutathione synthesis was beneficial to maintain redox homeostasis under oxidative or nutrient stress, consequently exerting beneficial impact on cell survival [19]. The transplantation of adipose-derived mesenchymal stem cells (Ad-MSCs) in $1 \mathrm{ml}$ of Dulbecco's modified Eagle's medium (DMEM) was injected into articular defect area of the osteoarthritis rabbits, and the overall healing score of experimental knees was superior when compared to the control group just received $1 \mathrm{ml}$ of DMEM, in which $2 \mathrm{mM} \mathrm{L-glutamine}$ was included [157]. In addition, when it comes to osteoarthritis patients who received TKA, supplementation with a combination of $\beta$ hydroxy- $\beta$-methyl butyrate, L-arginine, and L-glutamine (HMB/Arg/Gln) during the postoperative recovery could suppress the loss of muscle strength [150].

\section{Conclusion}

Recent evidences indicated that glutamine is a critical regulator in bone homeostasis via supporting energy as a substitute carbon source through TCA cycle and providing precursors for protein and nucleic acid synthesis. At cellular level, glutamine metabolism mediate the bioenergy of bone cells including BMSCs, osteoblasts, chondrocytes, and osteoclasts, thus influencing their capabilities of the proliferation, differentiation, and mineralization. Abnormal glutamine metabolism is associated with clinical disorders such as osteoporosis and osteoarthritis and expected to provide novel guideline for treatments. In bone tissues, an integrated regulatory network where glutamine acting as the target participate BMSC differentiation, whereas researches of 
TABLE 1: The application of glutamine in clinical trials.

\begin{tabular}{|c|c|c|}
\hline & Disorders/treatment/diagnosis & Detailed effect \\
\hline \multirow[t]{5}{*}{ Digestive system disease } & Postinfectious irritable bowel syndrome & $\begin{array}{l}\text { Restore tight junction proteins, increase claudin-1 } \\
\text { expression, and improve permeability [121] }\end{array}$ \\
\hline & Crohn's disease & $\begin{array}{l}\text { Increase the insoluble fraction of claudin-1 and } \\
\text { occludin proteins, prevent the tight junction proteins, } \\
\text { and maintain the intercellular junction [122] }\end{array}$ \\
\hline & Short bowel syndrome & $\begin{array}{l}\text { Provide energy for enterocytes, enhance the } \\
\text { transport of sodium and water in the ileum, and } \\
\text { upregulate intracellular protein synthesis [123-125] }\end{array}$ \\
\hline & Acute pancreatitis & $\begin{array}{l}\text { Improve lymphocyte proliferation, reduce } \\
\text { proinflammatory cytokine, release C-reactive protein, } \\
\text { and improve the nutritional status }[126,127]\end{array}$ \\
\hline & Cirrhotic & Increase blood ammonia [128] \\
\hline \multirow[t]{2}{*}{ Circulation system disease } & Sickle cell disease & $\begin{array}{c}\text { Raise the NAD redox ratio within sickle cells and } \\
\text { synthesize NAD and decrease endothelial cell adhesion in } \\
\text { sickled red cells }[129,130]\end{array}$ \\
\hline & Heart failure & $\begin{array}{l}\text { Maintain a positive nitrogen balance and activate the } \\
\text { suppressed oxidative metabolism [131] }\end{array}$ \\
\hline Locomotor system disease & Duchenne muscular dystrophy & $\begin{array}{l}\text { Inhibit whole-body protein degradation and stimulate } \\
\text { insulin secretion }[132,133]\end{array}$ \\
\hline \multirow[t]{4}{*}{ Systemic disorders } & Critically ill patients & Maintain high level of HSP70 [134] \\
\hline & Sepsis & $\begin{array}{l}\text { Increase immune response, donate nitrogen for many } \\
\text { anabolic processes, and promote wound healing [135] }\end{array}$ \\
\hline & Type 2 diabetes mellitus & $\begin{array}{l}\text { Delay gastric emptying to lower glycemia, stimulate } \\
\text { GLP-1 concentration, and increase circulating insulin }\end{array}$ \\
\hline & Low birthweight infants & $\begin{array}{l}\text { Aid in maturation of the intestinal tract enhances growth, } \\
\text { development, and function of the immunologic system }[136,137]\end{array}$ \\
\hline Imaging diagnosis & PET assay of tumor & A potential tumor biomarker for targeted radiotracer imaging [138] \\
\hline \multirow[t]{6}{*}{$\begin{array}{l}\text { Regulatory effect on } \\
\text { certain treatments }\end{array}$} & Radiotherapy-induced toxicities & Protective effects of diarrhea minimized dermatitis $[139,140]$ \\
\hline & Chemotherapy-induced toxicities & $\begin{array}{l}\text { Treat neuropathy induced by vincristine and decrease } \\
\text { mucositis severity }[141-144]\end{array}$ \\
\hline & Peripheral blood stem cell transplantation & Improve $\mathrm{CD}^{+}$and $\mathrm{CD} 4^{+}$lymphocyte recovery $[145,146]$ \\
\hline & Liver transplantation & $\begin{array}{l}\text { Synthesize glutathione and protect the liver graft } \\
\text { against lipid peroxidation [147] }\end{array}$ \\
\hline & Cardiac surgery & $\begin{array}{l}\text { Enhance cell survival, attenuate the systemic inflammatory } \\
\text { response, and prevent intracellular lactate accumulation }[148,149]\end{array}$ \\
\hline & Total knee replacement (TKA) & Suppress the loss of muscle strength after TKA [150] \\
\hline
\end{tabular}

downstream effectors of glutamine metabolism are seldom studied currently. Therefore, the mechanism of glutamine in bone homeostasis is likely multifaceted and additional basic investigation is needed beyond doubt. Glutamine metabolism has diversified influences on other cells or tissues, for example, it impacted the cellular differentiation through the epigenetic regulation in embryonic stem cells [158]; nevertheless, it has not been elucidated in bone cells. Alternatively, glutamine supplement has been applied in some systemic disease treatment and is expected to restore the impairment of osteoporosis and osteoarthritis. Virtually, the targets of glutamine in bone disease therapy are little known. Therefore, more fundamental and clinical studies are needed to deeply investigate the role of glutamine metabolism in regulating bone homeostasis and provide a new strategy for the clinical treatment of bone diseases.

\section{Conflicts of Interest}

The authors declare that there is no conflict of interest regarding the publication of this paper.

\section{Authors' Contributions}

Tao Zhou and Yuqing Yang contributed equally.

\section{Acknowledgments}

This work was supported by grants from the National Natural Science Foundation of China (NSFC, 81600842, 81621062, and 81520108009) and the Innovative Spark Program of Sichuan University (2018SCUH0056). 


\section{References}

[1] H. K. Datta, W. F. Ng, J. A. Walker, S. P. Tuck, and S. S. Varanasi, "The cell biology of bone metabolism," Journal of Clinical Pathology, vol. 61, no. 5, pp. 577-587, 2008.

[2] P. Katsimbri, "The biology of normal bone remodelling," European Journal of Cancer Care, vol. 26, no. 6, 2017.

[3] G. Karsenty, H. M. Kronenberg, and C. Settembre, "Genetic control of bone formation," Annual Review of Cell and Developmental Biology, vol. 25, no. 1, pp. 629-648, 2009.

[4] T. A. P. Fernandes, L. M. L. Gonçalves, and J. A. A. Brito, "Relationships between bone turnover and energy metabolism," Journal of Diabetes Research, vol. 2017, 11 pages, 2017.

[5] M. Prideaux, D. M. Findlay, and G. J. Atkins, "Osteocytes: the master cells in bone remodelling," Current Opinion in Pharmacology, vol. 28, pp. 24-30, 2016.

[6] K. Fukasawa, G. Park, T. Iezaki et al., "ATF3 controls proliferation of osteoclast precursor and bone remodeling," Scientific Reports, vol. 6, no. 1, 2016.

[7] K. J. Suchacki, F. Roberts, A. Lovdel et al., "Skeletal energy homeostasis: a paradigm of endocrine discovery," The Journal of Endocrinology, vol. 234, no. 1, pp. R67-r79, 2017.

[8] D. F. Rolfe and G. C. Brown, "Cellular energy utilization and molecular origin of standard metabolic rate in mammals," Physiological Reviews, vol. 77, no. 3, pp. 731-758, 1997.

[9] S. Hui, J. M. Ghergurovich, R. J. Morscher et al., "Glucose feeds the TCA cycle via circulating lactate," Nature, vol. 551, no. 7678, pp. 115-118, 2017.

[10] P. E. Porporato, V. L. Payen, B. Baselet, and P. Sonveaux, "Metabolic changes associated with tumor metastasis, part 2: mitochondria, lipid and amino acid metabolism," Cellular and Molecular Life Sciences, vol. 73, no. 7, pp. 1349-1363, 2016.

[11] P. Kumar and K. K. Dubey, "Modulation of fatty acid metabolism and tricarboxylic acid cycle to enhance the lipstatin production through medium engineering in Streptomyces toxytricini," Bioresource Technology, vol. 213, pp. 64-68, 2016.

[12] R. C. Riddle and T. L. Clemens, "Bone cell bioenergetics and skeletal energy homeostasis," Physiological Reviews, vol. 97, no. 2, pp. 667-698, 2017.

[13] M. S. Cooper, M. J. Seibel, and H. Zhou, "Glucocorticoids, bone and energy metabolism,” Bone, vol. 82, pp. 64-68, 2016.

[14] D. E. Biancur, J. A. Paulo, B. Małachowska et al., "Compensatory metabolic networks in pancreatic cancers upon perturbation of glutamine metabolism," Nature Communications, vol. 8, no. 1, 2017.

[15] H. Huang, S. Vandekeere, J. Kalucka et al., "Role of glutamine and interlinked asparagine metabolism in vessel formation," The EMBO Journal, vol. 36, no. 16, pp. 2334-2352, 2017.

[16] S. Yao, C. Li, M. Beckley, and D. Liu, "Expression of odontogenic ameloblast-associated protein in the dental follicle and its role in osteogenic differentiation of dental follicle stem cells," Archives of Oral Biology, vol. 78, pp. 6-12, 2017.

[17] Y. Yu, H. Newman, L. Shen et al., "Glutamine metabolism regulates proliferation and lineage allocation in skeletal stem cells," Cell Metabolism, vol. 29, no. 4, pp. 966-978.e4, 2019.

[18] A. Olkku and A. Mahonen, "Wnt and steroid pathways control glutamate signalling by regulating glutamine synthetase activity in osteoblastic cells," Bone, vol. 43, no. 3, pp. 483-493, 2008.
[19] S. Stegen, N. van Gastel, G. Eelen et al., "HIF-1 $\alpha$ Promotes Glutamine-Mediated Redox Homeostasis and GlycogenDependent Bioenergetics to Support Postimplantation Bone Cell Survival," Cell Metabolism, vol. 23, no. 2, pp. 265-279, 2016.

[20] G. Shen, H. Zhang, P. Jia et al., "GOLM1 stimulation of glutamine metabolism promotes osteoporosis via inhibiting osteogenic differentiation of BMSCs," Cellular Physiology and Biochemistry, vol. 50, no. 5, pp. 1916-1928, 2018.

[21] J. R. Mayers and M. G. Vander Heiden, "Famine versus feast: understanding the metabolism of tumors in vivo," Trends in Biochemical Sciences, vol. 40, no. 3, pp. 130-140, 2015.

[22] J. Bergstrom, P. Furst, L. O. Noree, and E. Vinnars, "Intracellular free amino acid concentration in human muscle tissue," Journal of Applied Physiology, vol. 36, no. 6, pp. 693-697, 1974.

[23] B. I. Labow, W. W. Souba, and S. F. Abcouwer, "Mechanisms governing the expression of the enzymes of glutamine metabolism-glutaminase and glutamine synthetase," The Journal of Nutrition, vol. 131, no. 9, pp. 2467S-2474S, 2001.

[24] J. Neu, V. Shenoy, and R. Chakrabarti, "Glutamine nutrition and metabolism: where do we go from here?," FASEB Journal, vol. 10, no. 8, pp. 829-837, 1996.

[25] R. W. Moreadith and A. L. Lehninger, "The pathways of glutamate and glutamine oxidation by tumor cell mitochondria. Role of mitochondrial NAD(P)+-dependent malic enzyme," The Journal of Biological Chemistry, vol. 259, no. 10, pp. 6215-6221, 1984.

[26] A. M. Hosios, V. C. Hecht, L. V. Danai et al., "Amino acids rather than glucose account for the majority of cell mass in proliferating mammalian cells," Developmental Cell, vol. 36, no. 5, pp. 540-549, 2016.

[27] L. Alberghina and D. Gaglio, "Redox control of glutamine utilization in cancer," Cell Death \& Disease, vol. 5, no. 12, p. e1561, 2014.

[28] D. Patel, D. Menon, E. Bernfeld et al., "Aspartate rescues Sphase arrest caused by suppression of glutamine utilization in KRas-driven cancer cells," The Journal of Biological Chemistry, vol. 291, no. 17, pp. 9322-9329, 2016.

[29] K. Birsoy, T. Wang, W. W. Chen, E. Freinkman, M. AbuRemaileh, and D. M. Sabatini, "An essential role of the mitochondrial electron transport chain in cell proliferation is to enable aspartate synthesis," Cell, vol. 162, no. 3, pp. 540$551,2015$.

[30] L. B. Sullivan, D. Y. Gui, A. M. Hosios, L. N. Bush, E. Freinkman, and M. G. Vander Heiden, "Supporting aspartate biosynthesis is an essential function of respiration in proliferating cells," Cell, vol. 162, no. 3, pp. 552-563, 2015.

[31] P. S. Ward, J. Patel, D. R. Wise et al., "The Common Feature of Leukemia-Associated IDH1 and IDH2 Mutations Is a Neomorphic Enzyme Activity Converting $\alpha$-Ketoglutarate to 2-Hydroxyglutarate," Cancer Cell, vol. 17, no. 3, pp. 225234, 2010.

[32] E. R. Still and M. O. Yuneva, "Hopefully devoted to Q: targeting glutamine addiction in cancer," British Journal of Cancer, vol. 116, no. 11, pp. 1375-1381, 2017.

[33] A. Le, A. N. Lane, M. Hamaker et al., "Glucose-Independent Glutamine Metabolism via TCA Cycling for Proliferation and Survival in B Cells," Cell Metabolism, vol. 15, no. 1, pp. 110121, 2012. 
[34] R. J. DeBerardinis, A. Mancuso, E. Daikhin et al., "Beyond aerobic glycolysis: transformed cells can engage in glutamine metabolism that exceeds the requirement for protein and nucleotide synthesis," Proceedings of the National Academy of Sciences of the United States of America, vol. 104, no. 49, pp. 19345-19350, 2007.

[35] H. Cohen, H. Barash, I. Meivar-Levy et al., "The Wnt/ $\beta$ catenin pathway determines the predisposition and efficiency of liver-to-pancreas reprogramming," Hepatology, vol. 68, no. 4, pp. 1589-1603, 2018.

[36] V. Cruzat, M. Macedo Rogero, K. Noel Keane, R. Curi, and P. Newsholme, "Glutamine: metabolism and immune function, supplementation and clinical translation," Nutrients, vol. 10, no. 11, p. 1564, 2018.

[37] E. M. Palmieri, I. Spera, A. Menga, V. Infantino, V. Iacobazzi, and A. Castegna, "Glutamine synthetase desensitizes differentiated adipocytes to proinflammatory stimuli by raising intracellular glutamine levels," FEBS Letters, vol. 588, no. 24, pp. 4807-4814, 2014.

[38] D. A. Chisolm and A. S. Weinmann, "Metabolites, genome organization, and cellular differentiation gene programs," Current Opinion in Immunology, vol. 51, pp. 62-67, 2018.

[39] R. M. Biltz, J. M. Letteri, E. D. Pellegrino, A. Palekar, and L. M. Pinkus, "Glutamine metabolism in bone," Mineral and Electrolyte Metabolism, vol. 9, no. 3, pp. 125-131, 1983.

[40] P. Bianco and P. G. Robey, "Skeletal stem cells," Development, vol. 142, no. 6, pp. 1023-1027, 2015.

[41] J. Wu, W. Zhang, Q. Ran et al., "The differentiation balance of bone marrow mesenchymal stem cells is crucial to hematopoiesis," Stem Cells International, vol. 2018, 13 pages, 2018.

[42] L. Xie, X. Zeng, J. Hu, and Q. Chen, "Characterization of nestin, a selective marker for bone marrow derived mesenchymal stem cells," Stem Cells International, vol. 2015, 9 pages, 2015.

[43] A. Nuschke, M. Rodrigues, A. W. Wells, K. Sylakowski, and A. Wells, "Mesenchymal stem cells/multipotent stromal cells (MSCs) are glycolytic and thus glucose is a limiting factor of in vitro models of MSC starvation," Stem Cell Research \& Therapy, vol. 7, no. 1, p. 179, 2016.

[44] S. Tohyama, J. Fujita, T. Hishiki et al., "Glutamine oxidation is indispensable for survival of human pluripotent stem cells," Cell Metabolism, vol. 23, no. 4, pp. 663-674, 2016.

[45] N. Fillmore, A. Huqi, J. S. Jaswal et al., "Effect of fatty acids on human bone marrow mesenchymal stem cell energy metabolism and survival," PLoS One, vol. 10, no. 3, 2015.

[46] A. B. Borle, N. Nichols, and G. Nichols, "Metabolic studies of bone in vitro. I. Normal bone," The Journal of Biological Chemistry, vol. 235, no. 4, pp. 1206-1210, 1960.

[47] T. F. Dixon and H. R. Perkins, "Citric acid and bone metabolism," The Biochemical Journal, vol. 52, no. 2, pp. 260-265, 1952.

[48] L. C. Costello, R. B. Franklin, M. A. Reynolds, and M. Chellaiah, "The important role of osteoblasts and citrate production in bone formation: "osteoblast citration" as a new concept for an old relationship,", The Open Bone Journal, vol. 4, no. 1, pp. 27-34, 2012.

[49] A. Covic, M. Vervloet, Z. A. Massy et al., "Bone and mineral disorders in chronic kidney disease: implications for cardiovascular health and ageing in the general population," The Lancet Diabetes \& Endocrinology, vol. 6, no. 4, pp. 319-331, 2018.
[50] N. Bonnet, "Bone-derived factors: a new gateway to regulate glycemia," Calcified Tissue International, vol. 100, no. 2, pp. 174-183, 2017.

[51] K. M. Thrailkill, J. S. Nyman, R. C. Bunn et al., "The impact of SGLT2 inhibitors, compared with insulin, on diabetic bone disease in a mouse model of type 1 diabetes," Bone, vol. 94, pp. 141-151, 2017.

[52] W. C. Lee, A. R. Guntur, F. Long, and C. J. Rosen, "Energy metabolism of the osteoblast: implications for osteoporosis," Endocrine Reviews, vol. 38, no. 3, pp. 255-266, 2017.

[53] H. Eagle, V. I. Oyama, M. F. Levy, C. E. Horton, and R. Fleischman, "The growth response of mammalian cells in tissue culture to L-glutamine and L-glutamic acid," The Journal of Biological Chemistry, vol. 218, no. 2, pp. 607-616, 1956.

[54] S. L. Colombo, M. Palacios-Callender, N. Frakich et al., "Molecular basis for the differential use of glucose and glutamine in cell proliferation as revealed by synchronized HeLa cells," Proceedings of the National Academy of Sciences of the United States of America, vol. 108, no. 52, pp. 2106921074, 2011.

[55] E. Ahn, P. Kumar, D. Mukha, A. Tzur, and T. Shlomi, “Temporal fluxomics reveals oscillations in TCA cycle flux throughout the mammalian cell cycle," Molecular Systems Biology, vol. 13, no. 11, p. 953, 2017.

[56] P. Lenz, R. Pfeiffer, D. Baris et al., "Cell-cycle control in urothelial carcinoma: large-scale tissue array analysis of tumor tissue from Maine and Vermont," Cancer Epidemiology, Biomarkers \& Prevention, vol. 21, no. 9, pp. 1555-1564, 2012.

[57] L. Yuan, X. Sheng, A. K. Willson et al., "Glutamine promotes ovarian cancer cell proliferation through the mTOR/S6 pathway," Endocrine-Related Cancer, vol. 22, no. 4, pp. 577-591, 2015.

[58] B. Kim, J. Li, C. Jang, and Z. Arany, "Glutamine fuels proliferation but not migration of endothelial cells," The EMBO Journal, vol. 36, no. 16, pp. 2321-2333, 2017.

[59] D. R. Wise, P. S. Ward, J. E. S. Shay et al., "Hypoxia promotes isocitrate dehydrogenase-dependent carboxylation of -ketoglutarate to citrate to support cell growth and viability," Proceedings of the National Academy of Sciences of the United States of America, vol. 108, no. 49, pp. 19611-19616, 2011.

[60] P. A. Gameiro, J. Yang, A. M. Metelo et al., "In vivo HIFmediated reductive carboxylation is regulated by citrate levels and sensitizes VHL-deficient cells to glutamine deprivation," Cell Metabolism, vol. 17, no. 3, pp. 372-385, 2013.

[61] C. M. Metallo, P. A. Gameiro, E. L. Bell et al., "Reductive glutamine metabolism by IDH1 mediates lipogenesis under hypoxia," Nature, vol. 481, no. 7381, pp. 380-384, 2012.

[62] C. T. Chen, S. H. Hsu, and Y. H. Wei, "Mitochondrial bioenergetic function and metabolic plasticity in stem cell differentiation and cellular reprogramming," Biochimica et Biophysica Acta, vol. 1820, no. 5, pp. 571-576, 2012.

[63] T. M. Skerry, "The role of glutamate in the regulation of bone mass and architecture," Journal of Musculoskeletal \& Neuronal Interactions, vol. 8, no. 2, pp. 166-173, 2008.

[64] L. Deng, H. Hong, X. Zhang et al., "Down-regulated lncRNA MEG3 promotes osteogenic differentiation of human dental follicle stem cells by epigenetically regulating Wnt pathway," Biochemical and Biophysical Research Communications, vol. 503, no. 3, pp. 2061-2067, 2018. 
[65] Y. Chen, Y. R. Yang, X. L. Fan et al., "miR-206 inhibits osteogenic differentiation of bone marrow mesenchymal stem cells by targetting glutaminase," Bioscience Reports, vol. 39, no. 3, p. BSR20181108, 2019.

[66] $\mathrm{H}$. Wu, Z. Wu, P. Li et al., "Bone size and quality regulation: concerted actions of mTOR in mesenchymal stromal cells and osteoclasts," Stem Cell Reports, vol. 8, no. 6, pp. 16001616, 2017.

[67] C. M. Karner and F. Long, "Wnt signaling and cellular metabolism in osteoblasts," Cellular and Molecular Life Sciences, vol. 74, no. 9, pp. 1649-1657, 2017.

[68] C. M. Karner, E. Esen, A. L. Okunade, B. W. Patterson, and F. Long, "Increased glutamine catabolism mediates bone anabolism in response to WNT signaling," The Journal of Clinical Investigation, vol. 125, no. 2, pp. 551-562, 2015.

[69] A. Csibi, S. M. Fendt, C. Li et al., "The mTORC1 pathway stimulates glutamine metabolism and cell proliferation by repressing SIRT4," Cell, vol. 153, no. 4, pp. 840-854, 2013.

[70] J. Carnesecchi and J. M. Vanacker, "Estrogen-related receptors and the control of bone cell fate," Molecular and Cellular Endocrinology, vol. 432, pp. 37-43, 2016.

[71] X. D. Chen, S. Shi, T. Xu, P. G. Robey, and M. F. Young, "Agerelated osteoporosis in biglycan-deficient mice is related to defects in bone marrow stromal cells," Journal of Bone and Mineral Research, vol. 17, no. 2, pp. 331-340, 2002.

[72] T. Wang, H. He, S. Liu et al., "Autophagy: a promising target for age-related osteoporosis," Current Drug Targets, vol. 20, no. 3, pp. 354-365, 2019.

[73] T. Huang, R. Liu, X. Fu et al., "Aging reduces an ERRalphadirected mitochondrial glutaminase expression suppressing glutamine anaplerosis and osteogenic differentiation of mesenchymal stem cells," Stem Cells, vol. 35, no. 2, pp. 411424, 2017.

[74] E. Bonnelye, P. Reboul, N. Duval, M. Cardelli, and J. E. Aubin, "Estrogen receptor-related receptor $\alpha$ regulation by interleukin- $1 \beta$ in prostaglandin E2- and cAMP-dependent pathways in osteoarthritic chondrocytes," Arthritis and Rheumatism, vol. 63, no. 8, pp. 2374-2384, 2011.

[75] E. Bonnelye, N. Laurin, P. Jurdic, D. A. Hart, and J. E. Aubin, "Estrogen receptor-related receptor- $\alpha$ (ERR- $\alpha$ ) is dysregulated in inflammatory arthritis," Rheumatology, vol. 47, no. 12, pp. 1785-1791, 2008.

[76] M. Gallet, S. Saïdi, E. Haÿ et al., "Repression of Osteoblast Maturation by ERR $\alpha$ Accounts for Bone Loss Induced by Estrogen Deficiency," PLoS One, vol. 8, no. 1, p. e54837, 2013.

[77] C. Luo, E. Balsa, A. Thomas et al., "ERR $\alpha$ Maintains Mitochondrial Oxidative Metabolism and Constitutes an Actionable Target in PGC1 $\alpha$-Elevated Melanomas," Molecular Cancer Research, vol. 15, no. 10, pp. 1366-1375, 2017.

[78] E. Bonnelye and J. E. Aubin, "An energetic orphan in an endocrine tissue: a revised perspective of the function of estrogen receptor-related receptor alpha in bone and cartilage," Journal of Bone and Mineral Research, vol. 28, no. 2, pp. 225-233, 2013.

[79] S. S. Sabharwal and P. T. Schumacker, "Mitochondrial ROS in cancer: initiators, amplifiers or an Achilles' heel?," Nature Reviews. Cancer, vol. 14, no. 11, pp. 709-721, 2014.

[80] E. Holzerova and H. Prokisch, "Mitochondria: much ado about nothing? How dangerous is reactive oxygen species production?," The International Journal of Biochemistry \& Cell Biology, vol. 63, pp. 16-20, 2015.

[81] W. Geng, H. Shi, X. Zhang, W. Tan, Y. Cao, and R. Mei, "Substance P enhances BMSC osteogenic differentiation via autophagic activation," Molecular Medicine Reports, vol. 20, no. 1, pp. 664-670, 2019.

[82] N. Shyh-Chang, G. Q. Daley, and L. C. Cantley, "Stem cell metabolism in tissue development and aging," Development, vol. 140, no. 12, pp. 2535-2547, 2013.

[83] D. A. Callaway and J. X. Jiang, "Reactive oxygen species and oxidative stress in osteoclastogenesis, skeletal aging and bone diseases," Journal of Bone and Mineral Metabolism, vol. 33, no. 4, pp. 359-370, 2015.

[84] K. Singh, L. Krug, A. Basu et al., "Alpha-ketoglutarate curbs differentiation and induces cell death in mesenchymal stromal precursors with mitochondrial dysfunction," Stem Cells, vol. 35, no. 7, pp. 1704-1718, 2017.

[85] K. V. Tormos, E. Anso, R. B. Hamanaka et al., "Mitochondrial complex III ROS regulate adipocyte differentiation," Cell Metabolism, vol. 14, no. 4, pp. 537-544, 2011.

[86] W. Wang, Y. Zhang, W. Lu, and K. Liu, "Mitochondrial reactive oxygen species regulate adipocyte differentiation of mesenchymal stem cells in hematopoietic stress induced by arabinosylcytosine," PLoS One, vol. 10, no. 3, p. e0120629, 2015.

[87] M. E. Bernardo and W. E. Fibbe, "Mesenchymal stromal cells and hematopoietic stem cell transplantation," Immunology Letters, vol. 168, no. 2, pp. 215-221, 2015.

[88] M. W. Lee, S. Ryu, D. S. Kim, K. W. Sung, H. H. Koo, and K. H. Yoo, "Strategies to improve the immunosuppressive properties of human mesenchymal stem cells," Stem Cell Research \& Therapy, vol. 6, no. 1, 2015.

[89] M. Wang, Q. Yuan, and L. Xie, "Mesenchymal stem cellbased immunomodulation: properties and clinical application," Stem Cells International, vol. 2018, 12 pages, 2018.

[90] E. Sasaki, T. Umeda, I. Takahashi et al., "Effect of glutamine supplementation on neutrophil function in male judoists," Luminescence, vol. 28, no. 4, pp. 442-449, 2013.

[91] T. Sartori, G. Galvão dos Santos, A. Nogueira-Pedro et al., "Effects of glutamine, taurine and their association on inflammatory pathway markers in macrophages," Inflammopharmacology, vol. 26, no. 3, pp. 829-838, 2018.

[92] F. Wasinski, M. F. Gregnani, F. H. Ornellas et al., "Lymphocyte glucose and glutamine metabolism as targets of the anti-inflammatory and immunomodulatory effects of exercise," Mediators of Inflammation, vol. 2014, 10 pages, 2014.

[93] D. Qian, G. Wei, C. Xu et al., "Bone marrow-derived mesenchymal stem cells (BMSCs) repair acute necrotized pancreatitis by secreting microRNA- 9 to target the NF- $\kappa \mathrm{B} 1 / \mathrm{p} 50$ gene in rats," Scientific Reports, vol. 7, no. 1, p. 581, 2017.

[94] R. Ganesan and M. Rasool, "Interleukin 17 regulates SHP-2 and IL-17RA/STAT-3 dependent Cyr61, IL-23 and GMCSF expression and RANKL mediated osteoclastogenesis by fibroblast-like synoviocytes in rheumatoid arthritis," Molecular Immunology, vol. 91, pp. 134-144, 2017.

[95] Y. Sun, J. Ma, D. Li et al., "Interleukin-10 inhibits interleukin$1 \beta$ production and inflammasome activation of microglia in epileptic seizures," Journal of Neuroinflammation, vol. 16, no. 1, p. 66, 2019.

[96] D. E. Levy and C. K. Lee, "What does Stat3 do?," The Journal of Clinical Investigation, vol. 109, no. 9, pp. 1143-1148, 2002. 
[97] G. G. Dos Santos, A. A. Hastreiter, T. Sartori, P. Borelli, and R. A. Fock, "L-Glutamine in vitro modulates some immunomodulatory properties of bone marrow mesenchymal stem cells," Stem Cell Reviews and Reports, vol. 13, no. 4, pp. 482-490, 2017.

[98] P. Sukho, J. W. Hesselink, N. Kops, J. Kirpensteijn, F. Verseijden, and Y. M. Bastiaansen-Jenniskens, "Human mesenchymal stromal cell sheets induce macrophages predominantly to an anti-inflammatory phenotype," Stem Cells and Development, vol. 27, no. 13, pp. 922-934, 2018.

[99] M. Capulli, R. Paone, and N. Rucci, "Osteoblast and osteocyte: games without frontiers," Archives of Biochemistry and Biophysics, vol. 561, pp. 3-12, 2014.

[100] P. M. Brown, J. D. Hutchison, and J. C. Crockett, "Absence of glutamine supplementation prevents differentiation of murine calvarial osteoblasts to a mineralizing phenotype," Calcified Tissue International, vol. 89, no. 6, pp. 472-482, 2011.

[101] G. Bellon, B. Chaqour, Y. Wegrowski, J. C. Monboisse, and J. P. Borel, "Glutamine increases collagen gene transcription in cultured human fibroblasts," Biochimica et Biophysica Acta, vol. 1268, no. 3, pp. 311-323, 1995.

[102] J. Masson, M. Darmon, A. Conjard et al., "Mice lacking brain/kidney phosphate-activated glutaminase have impaired glutamatergic synaptic transmission, altered breathing, disorganized goal-directed behavior and die shortly after birth," The Journal of Neuroscience, vol. 26, no. 17, pp. 4660-4671, 2006.

[103] J. Melrose, C. Shu, J. M. Whitelock, and M. S. Lord, “The cartilage extracellular matrix as a transient developmental scaffold for growth plate maturation," Matrix Biology, vol. 52-54, pp. 363-383, 2016.

[104] C. J. Handley, G. Speight, K. M. Leyden, and D. A. Lowther, "Extracellular matrix metabolism by chondrocytes 7 . Evidence that L-glutamine is an essential amino acid for chondrocytes and other connective tissue cells," Biochimica et Biophysica Acta, vol. 627, no. 3, pp. 324-331, 1980.

[105] R. Rajpurohit, C. J. Koch, Z. Tao, C. M. Teixeira, and I. M. Shapiro, "Adaptation of chondrocytes to low oxygen tension: relationship between hypoxia and cellular metabolism," Journal of Cellular Physiology, vol. 168, no. 2, pp. 424-432, 1996.

[106] C. Maes, E. Araldi, K. Haigh et al., "VEGF-independent cellautonomous functions of HIF- $1 \alpha$ regulating oxygen consumption in fetal cartilage are critical for chondrocyte survival," Journal of Bone and Mineral Research, vol. 27, no. 3, pp. 596-609, 2012.

[107] J. Yu, F. Liang, H. Huang, P. Pirttiniemi, and D. Yu, "Effects of loading on chondrocyte hypoxia, HIF- $1 \alpha$ and VEGF in the mandibular condylar cartilage of young rats," Orthodontics \& Craniofacial Research, vol. 21, no. 1, pp. 41-47, 2018.

[108] S. Stegen, K. Laperre, G. Eelen et al., "HIF- $1 \alpha$ metabolically controls collagen synthesis and modification in chondrocytes," Nature, vol. 565, no. 7740, pp. 511-515, 2019.

[109] J. N. Gouze, K. Bordji, S. Gulberti et al., "Interleukin-1 $\beta$ down-regulates the expression of glucuronosyltransferase I, a key enzyme priming glycosaminoglycan biosynthesis: Influence of glucosamine on interleukin- $1 \beta$-mediated effects in rat chondrocytes," Arthritis and Rheumatism, vol. 44, no. 2, pp. 351-360, 2001.

[110] R. Issa, M. Boeving, M. Kinter, and T. M. Griffin, "Effect of biomechanical stress on endogenous antioxidant networks in bovine articular cartilage," Journal of Orthopaedic Research, vol. 36, no. 2, pp. 760-769, 2018.

[111] H. Tonomura, K. A. Takahashi, O. Mazda et al., "Glutamine protects articular chondrocytes from heat stress and NOinduced apoptosis with HSP70 expression," Osteoarthritis and Cartilage, vol. 14, no. 6, pp. 545-553, 2006.

[112] J. H. Kim, K. Kim, I. Kim, S. Seong, K. B. Lee, and N. Kim, "BCAP promotes osteoclast differentiation through regulation of the p38-dependent CREB signaling pathway," Bone, vol. 107, pp. 188-195, 2018.

[113] Y. Indo, S. Takeshita, K. A. Ishii et al., "Metabolic regulation of osteoclast differentiation and function," Journal of Bone and Mineral Research, vol. 28, no. 11, pp. 2392-2399, 2013.

[114] N. Utsunomiya-Tate, H. Endou, and Y. Kanai, "Cloning and functional characterization of a system ASC-like Na+-dependent neutral amino acid transporter," The Journal of Biological Chemistry, vol. 271, no. 25, pp. 14883-14890, 1996.

[115] P. Nicklin, P. Bergman, B. Zhang et al., "Bidirectional transport of amino acids regulates mTOR and autophagy," Cell, vol. 136, no. 3, pp. 521-534, 2009.

[116] G. Cooney, R. Curi, A. Mitchelson, P. Newsholme, M. Simpson, and E. A. Newsholme, "Activities of some key enzymes of carbohydrate, ketone body, adenosine and glutamine metabolism in liver, and brown and white adipose tissues of the rat," Biochemical and Biophysical Research Communications, vol. 138, no. 2, pp. 687-692, 1986.

[117] R. J. DeBerardinis, J. J. Lum, G. Hatzivassiliou, and C. B. Thompson, "The biology of cancer: metabolic reprogramming fuels cell growth and proliferation," Cell Metabolism, vol. 7, no. 1, pp. 11-20, 2008.

[118] H. Soh, M. Wasa, and M. Fukuzawa, "Hypoxia upregulates amino acid transport in a human neuroblastoma cell line," Journal of Pediatric Surgery, vol. 42, no. 4, pp. 608-612, 2007.

[119] K. J. Morten, L. Badder, and H. J. Knowles, "Differential regulation of HIF-mediated pathways increases mitochondrial metabolism and ATP production in hypoxic osteoclasts," The Journal of Pathology, vol. 229, no. 5, pp. 755-764, 2013.

[120] T. M. Griffin, K. M. Humphries, M. Kinter, H. Y. Lim, and L. I. Szweda, "Nutrient sensing and utilization: getting to the heart of metabolic flexibility," Biochimie, vol. 124, pp. 74-83, 2016.

[121] Q. Zhou, M. L. Verne, J. Z. Fields et al., "Randomised placebo-controlled trial of dietary glutamine supplements for postinfectious irritable bowel syndrome," Gut, vol. 68, no. 6, pp. 996-1002, 2018

[122] J. Benjamin, G. Makharia, V. Ahuja et al., "Glutamine and whey protein improve intestinal permeability and morphology in patients with Crohn's disease: a randomized controlled trial," Digestive Diseases and Sciences, vol. 57, no. 4, pp. 10001012, 2012.

[123] T. A. Byrne, D. W. Wilmore, K. Iyer et al., "Growth hormone, glutamine, and an optimal diet reduces parenteral nutrition in patients with short bowel syndrome: a prospective, randomized, placebo-controlled, double-blind clinical trial," Annals of Surgery, vol. 242, no. 5, pp. 655-661, 2005.

[124] G. H. Wu, Z. H. Wu, and Z. G. Wu, "Effects of bowel rehabilitation and combined trophic therapy on intestinal adaptation in short bowel patients," World Journal of Gastroenterology, vol. 9, no. 11, pp. 2601-2604, 2003.

[125] M. Guo, Y. Li, and J. Li, "Effect of growth hormone, glutamine, and enteral nutrition on intestinal adaptation in 
patients with short bowel syndrome," The Turkish Journal of Gastroenterology, vol. 24, no. 6, pp. 463-468, 2013.

[126] X. Liu, X. F. Sun, and Q. X. Ge, "The role of glutamine supplemented total parenteral nutrition (TPN) in severe acute pancreatitis," European Review for Medical and Pharmacological Science, vol. 20, no. 19, pp. 4176-4180, 2016.

[127] A. C. de Beaux, M. G. O’Riordain, J. A. Ross, L. Jodozi, D. C. Carter, and K. C. H. Fearon, "Glutamine-supplemented total parenteral nutrition reduces blood mononuclear cell interleukin-8 release in severe acute pancreatitis," Nutrition, vol. 14, no. 3, pp. 261-265, 1998.

[128] A. Masini, C. Efrati, M. Merli et al., "Effect of blood ammonia elevation following oral glutamine load on the psychometric performance of cirrhotic patients," Metabolic Brain Disease, vol. 18, no. 1, pp. 27-35, 2003.

[129] Y. Niihara, S. T. Miller, J. Kanter et al., "A Phase 3 Trial of l-Glutamine in Sickle Cell Disease," The New England Journal of Medicine, vol. 379, no. 3, pp. 226-235, 2018.

[130] D. W. Wilmore, "Food and Drug Administration approval of glutamine for sickle cell disease: success and precautions in glutamine research," Journal of Parenteral and Enteral Nutrition, vol. 41, no. 6, pp. 912-917, 2017.

[131] C. Wu, T. S. Kato, R. Ji et al., "Supplementation ofl-Alanyl-l-Glutamine and Fish Oil Improves Body Composition and Quality of Life in Patients With Chronic Heart Failure," Circulation. Heart Failure, vol. 8, no. 6, pp. 1077-1087, 2015.

[132] E. Mok, C. E. D. Violante, C. Daubrosse et al., "Oral glutamine and amino acid supplementation inhibit whole-body protein degradation in children with Duchenne muscular dystrophy," The American Journal of Clinical Nutrition, vol. 83, no. 4, pp. 823-828, 2006.

[133] G. Letellier, E. Mok, C. Alberti et al., "Effect of glutamine on glucose metabolism in children with Duchenne muscular dystrophy," Clinical Nutrition, vol. 32, no. 3, pp. 386-390, 2013.

[134] I. Jordan, M. Balaguer, M. E. Esteban et al., "Glutamine effects on heat shock protein 70 and interleukines 6 and 10: randomized trial of glutamine supplementation versus standard parenteral nutrition in critically ill children," Clinical Nutrition, vol. 35, no. 1, pp. 34-40, 2016.

[135] G. M. Koksal, E. Erbabacan, Y. Tunali, G. Karaoren, S. Vehid, and $\mathrm{H} . \mathrm{Oz}$, "The effects of intravenous, enteral and combined administration of glutamine on malnutrition in sepsis: a randomized clinical trial," Asia Pacific Journal of Clinical Nutrition, vol. 23, no. 1, pp. 34-40, 2014.

[136] J. M. Lacey, J. B. Crouch, K. Benfell et al., “The effects of glutamine-supplemented parenteral nutrition in premature infants," Journal of Parenteral and Enteral Nutrition, vol. 20, no. 1, pp. 74-80, 1996.

[137] R. A. Ehrenkranz, A. Das, L. A. Wrage et al., "Early nutrition mediates the influence of severity of illness on extremely LBW infants," Pediatric Research, vol. 69, no. 6, pp. 522529, 2011.

[138] M. P. S. Dunphy, J. J. Harding, S. Venneti et al., "In Vivo PET Assay of Tumor Glutamine Flux and Metabolism: In-Human Trial of18F-(2S,4R)-4-Fluoroglutamine," Radiology, vol. 287, no. 2, pp. 667-675, 2018.

[139] K. Eda, K. Uzer, T. Murat, and U. Cenk, "The effects of enteral glutamine on radiotherapy induced dermatitis in breast cancer," Clinical Nutrition, vol. 35, no. 2, pp. 436439, 2016.

[140] E. Kucuktulu, A. Guner, I. Kahraman, M. Topbas, and U. Kucuktulu, "The protective effects of glutamine on radiation-induced diarrhea," Supportive Care in Cancer, vol. 21, no. 4, pp. 1071-1075, 2013.

[141] T. A. K. A. E. TSUJIMOTO, Y. YAMAMOTO, M. WASA et al., "L-glutamine decreases the severity of mucositis induced by chemoradiotherapy in patients with locally advanced head and neck cancer: A double-blind, randomized, placebo-controlled trial," Oncology Reports, vol. 33, no. 1, pp. 33-39, 2015.

[142] Y. Tanaka, T. Takahashi, K. Yamaguchi, S. Osada, T. Shimokawa, and K. Yoshida, "Elemental diet plus glutamine for the prevention of mucositis in esophageal cancer patients receiving chemotherapy: a feasibility study," Supportive Care in Cancer, vol. 24, no. 2, pp. 933-941, 2016.

[143] S. C. Chang, Y. C. Lai, J. C. Hung, and C. Y. Chang, "Oral glutamine supplements reduce concurrent chemoradiotherapyinduced esophagitis in patients with advanced non-small cell lung cancer," Medicine (Baltimore), vol. 98, no. 8, p. e14463, 2019.

[144] S. Sands, E. J. Ladas, K. M. Kelly et al., "Glutamine for the treatment of vincristine-induced neuropathy in children and adolescents with cancer," Supportive Care in Cancer, vol. 25, no. 3, pp. 701-708, 2017.

[145] N. Piccirillo, S. de Matteis, L. Laurenti et al., "Glutamineenriched parenteral nutrition after autologous peripheral blood stem cell transplantation: effects on immune reconstitution and mucositis," Haematologica, vol. 88, no. 2, pp. 192-200, 2003.

[146] R. Pytlik, E. Gregora, P. Benes, and T. Kozak, "Effect of parenteral glutamine on restoration of lymphocyte subpopulations after high-dose chemotherapy and autologous hematopoietic cell transplantation: data from a doubleblind randomized study," Epidemiologie, Mikrobiologie, Imunologie, vol. 51, no. 4, pp. 152-155, 2002.

[147] M. A. P. Barros, P. R. L. Vasconcelos, C. M. Souza et al., "LAlanyl-glutamine attenuates oxidative stress in liver transplantation patients," Transplantation Proceedings, vol. 47, no. 8, pp. 2478-2482, 2015.

[148] M. N. Hissa, R. C. . Vasconcelos, S. B. Guimarães, R. P. Silva, J. H. P. Garcia, and P. R. L. . Vasconcelos, "Preoperative glutamine infusion improves glycemia in heart surgery patients," Acta Cirurgica Brasileira, vol. 26, Suppl 1, pp. 77-81, 2011.

[149] M. Chávez-Tostado, F. Carrillo-Llamas, P. E. MartínezGutiérrez et al., "Oral glutamine reduces myocardial damage after coronary revascularization under cardiopulmonary bypass. A randomized clinical trial," Nutrición Hospitalaria, vol. 34, no. 2, pp. 277-283, 2017.

[150] K. Nishizaki, H. Ikegami, Y. Tanaka, R. Imai, and H. Matsumura, "Effects of supplementation with a combination of $\beta$-hydroxy- $\beta$-methyl butyrate, $\mathrm{L}$-arginine, and $\mathrm{L}$ glutamine on postoperative recovery of quadriceps muscle strength after total knee arthroplasty," Asia Pacific Journal of Clinical Nutrition, vol. 24, no. 3, pp. 412-420, 2015.

[151] J. A. Eisman, E. R. Bogoch, R. Dell et al., "Making the first fracture the last fracture: ASBMR task force report on secondary fracture prevention," Journal of Bone and Mineral Research, vol. 27, no. 10, pp. 2039-2046, 2012. 
[152] O. Polat, S. S. Kilicoglu, and E. Erdemli, "A controlled trial of glutamine effects on bone healing," Advances in Therapy, vol. 24, no. 1, pp. 154-160, 2007.

[153] E. TOMASZEWSKA, P. DOBROWOLSKI, Ł. PROST, M. HUŁAS-STASIAK, S. MUSZYŃSKI, and T. BLICHARSKI, "The effect of supplementation of a glutamine precursor on the growth plate, articular cartilage and cancellous bone in fundectomy-induced osteopenic bone," The Journal of Veterinary Medical Science, vol. 78, no. 4, pp. 563-571, 2016.

[154] P. Dobrowolski, E. Tomaszewska, S. Muszynski, T. Blicharski, and S. G. Pierzynowski, "Dietary 2oxoglutarate prevents bone loss caused by neonatal treatment with maximal dexamethasone dose," Experimental Biology and Medicine, vol. 242, no. 7, pp. 671-682, 2017.

[155] A. C. Thomas, T. Hubbard-Turner, E. A. Wikstrom, and R. M. Palmieri-Smith, "Epidemiology of posttraumatic osteoarthritis," Journal of Athletic Training, vol. 52, no. 6, pp. 491-496, 2017.

[156] S. Fujita, Y. Arai, S. Nakagawa et al., "Combined microwave irradiation and intraarticular glutamine administrationinduced HSP70 expression therapy prevents cartilage degradation in a rat osteoarthritis model," Journal of Orthopaedic Research, vol. 30, no. 3, pp. 401-407, 2012.

[157] D. Mehrabani, M. Babazadeh, N. Tanideh et al., “The healing effect of adipose-derived mesenchymal stem cells in full-thickness femoral articular cartilage defects of rabbit," International Journal of Organ Transplantation Medicine, vol. 6, no. 4, pp. 165-175, 2015.

[158] B. W. Carey, L. W. S. Finley, J. R. Cross, C. D. Allis, and C. B. Thompson, "Intracellular $\alpha$-ketoglutarate maintains the pluripotency of embryonic stem cells," Nature, vol. 518, no. 7539, pp. 413-416, 2015. 


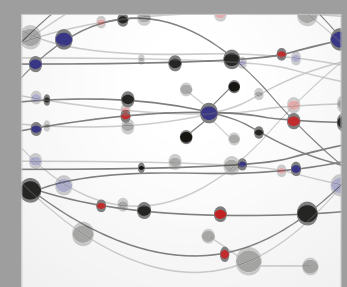

The Scientific World Journal
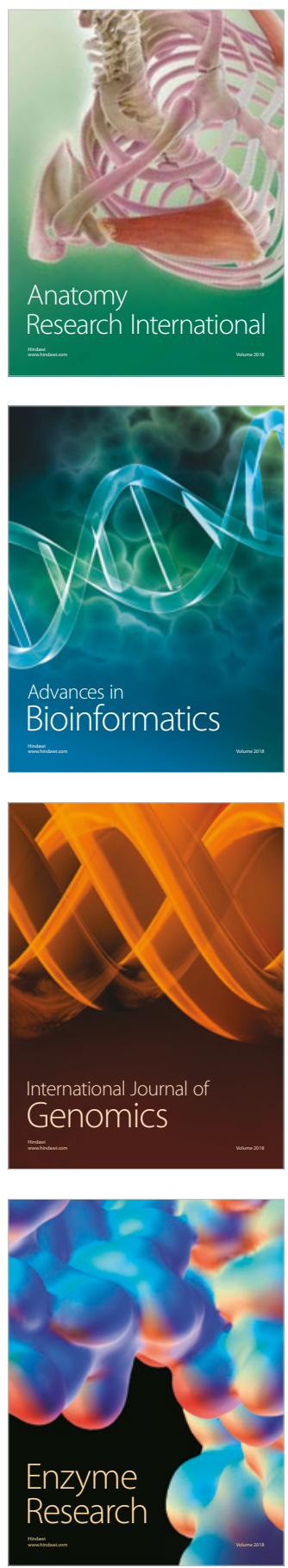
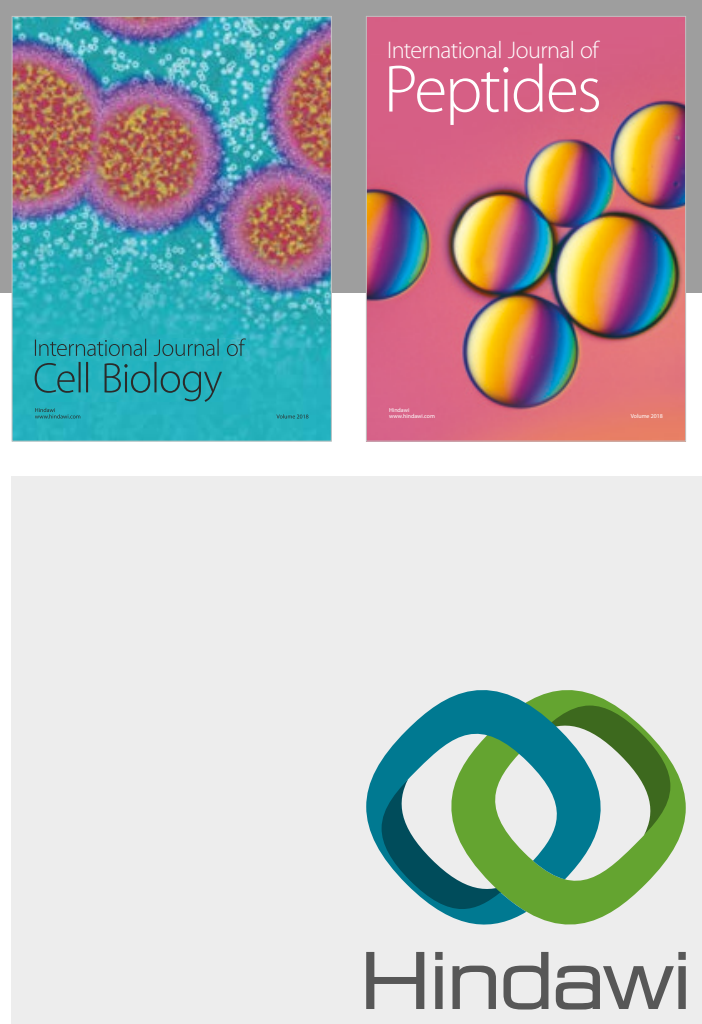

Submit your manuscripts at

www.hindawi.com
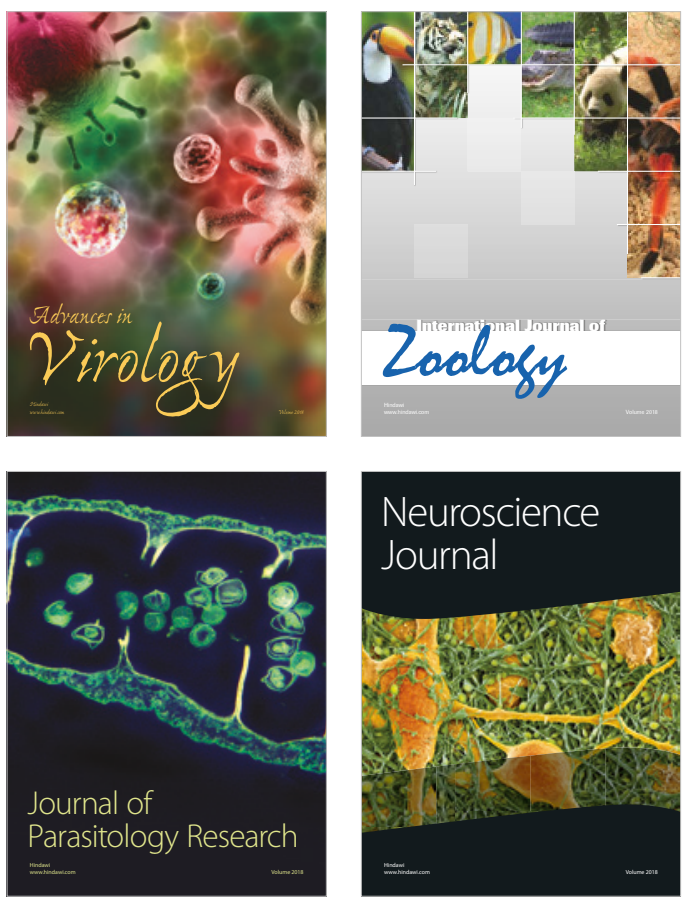
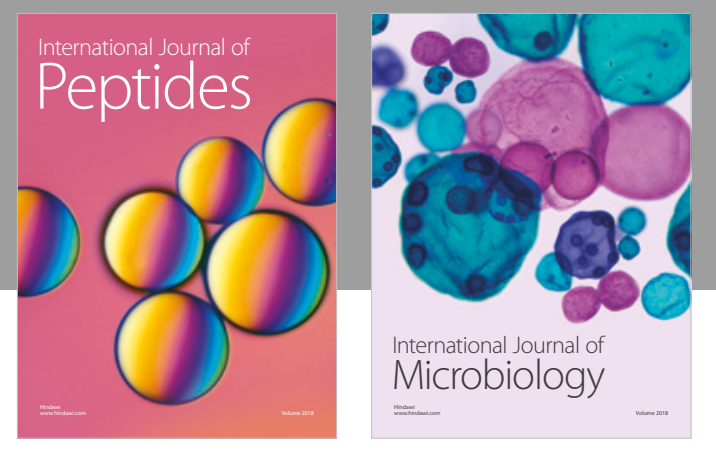

nternational Journal of Microbiology
Journal of
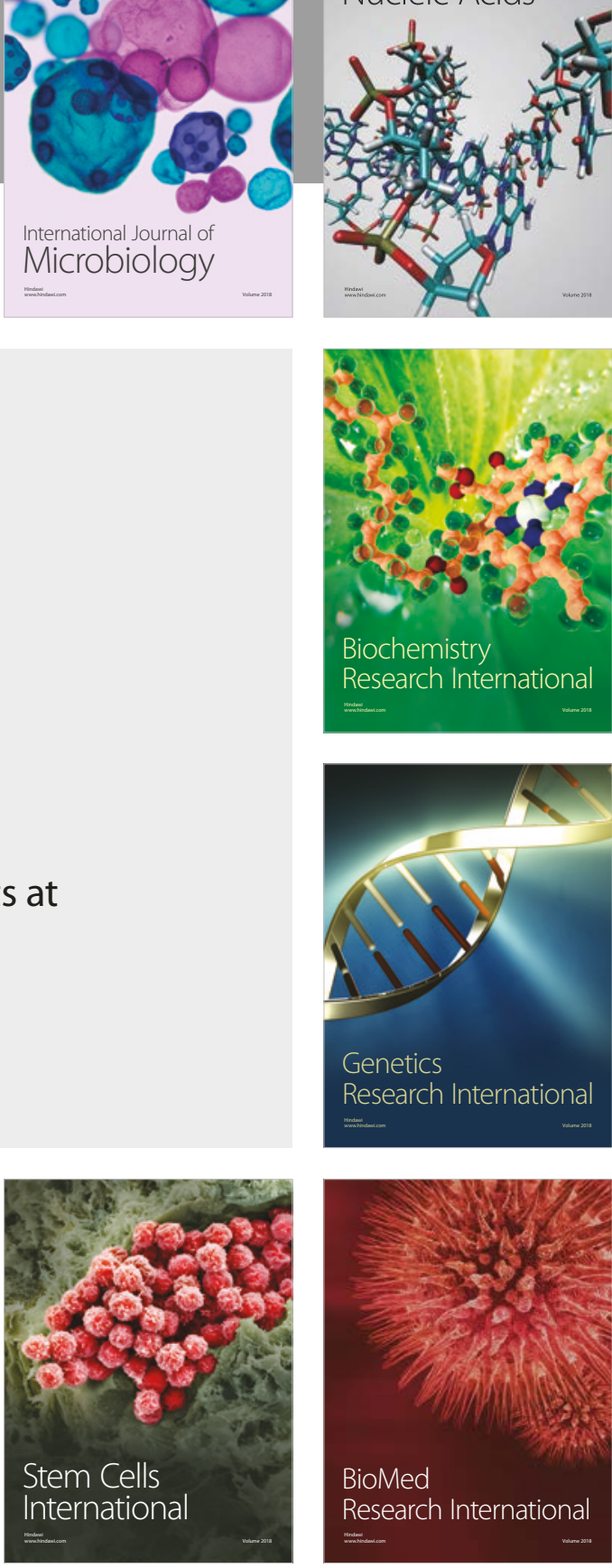
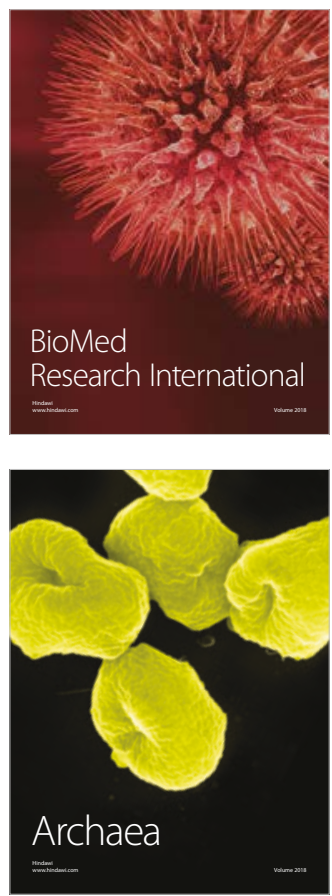